\title{
RESEARCH
}

Open Access

\section{Magnesium-enriched microenvironment promotes odontogenic differentiation in human dental pulp stem cells by activating ERK/BMP2/Smads signaling}

Yuanyuan Kong ${ }^{1,2}$, Xiaoli Hü ${ }^{3}$, Yingqun Zhong ${ }^{3}$, Ke Xu ${ }^{3}$, Buling $\mathrm{Wu}^{1 *}$ and Jianmao Zheng ${ }^{3,4^{*}}$ (D)

\begin{abstract}
Background: Magnesium $\left(\mathrm{Mg}^{2+}\right)$-enriched microenvironment promotes odontogenic differentiation in human dental pulp stem cells (DPSCs), but the regulatory mechanisms remain undefined. The aim of this work was to assess magnesium's function in the above process and to explore the associated signaling pathway.

Methods: DPSCs underwent culture in odontogenic medium with the addition of $0,1,5$, or $10 \mathrm{mM} \mathrm{MgCl}$. Intracellular $\mathrm{Mg}^{2+}$ levels in DPSCs were evaluated flow cytometrically using Mag-Fluo-4-AM. $\mathrm{Mg}^{2+}$-entry was inhibited by TRPM7 inhibitor 2-aminoethoxydiphenyl borate (2-APB). RNA-Sequencing was carried out for assessing transcriptome alterations in DPSCs during odontogenic differentiation associated with high extracellular $\mathrm{Mg}^{2+}$. KEGG pathway analysis was performed to determine pathways related to the retrieved differentially expressed genes (DEGs). Immunoblot was performed for assessing magnesium's role and exploring ERK/BMP2/Smads signaling.

Results: $\mathrm{Mg}^{2+}$-enriched microenvironment promoted odontogenic differentiation in DPSCs via intracellular $\mathrm{Mg}^{2+}$ increase. Consistently, the positive effect of high extracellular $\mathrm{Mg}^{2+}$ on odontogenic differentiation in DPSCs was blocked by 2-APB, which reduced $\mathrm{Mg}^{2+}$ entry. RNA-sequencing identified 734 DEGs related to odontogenic differentiation in DPSCs in the presence of high extracellular $\mathrm{Mg}^{2+}$. These DEGs participated in many cascades such as MAPK and TGF- $\beta$ pathways. Consistently, ERK and BMP2/Smads pathways were activated in DPSCs treated with high extracellular $\mathrm{Mg}^{2+}$. In agreement, ERK signaling inhibition by U0126 blunted the effect of high extracellular $\mathrm{Mg}^{2+}$ on mineralization and odontogenic differentiation in DPSCs. Interestingly, BMP2, BMPR1, and phosphorylated Smad1/5/9 were significantly decreased by U0126, indicating that BMP2/Smads acted as downstream of ERK.

Conclusions: $\mathrm{Mg}^{2+}$-enriched microenvironment promotes odontogenic differentiation in DPSCs by activating ERK BMP2/Smads signaling via intracellular $\mathrm{Mg}^{2+}$ increase. This study revealed that $\mathrm{Mg}^{2+}$-enriched microenvironment could be used as a new strategy for dental pulp regeneration.
\end{abstract}

Keywords: Magnesium-enriched microenvironment, ERK, BMP2, Odontogenic differentiation, DPSC

\footnotetext{
* Correspondence: bulingwu@smu.edu.cn; zhengjm25@mail.sysu.edu.cn

${ }^{1}$ Department of Stomatology, Nanfang Hospital, College of Stomatology,

Southern Medical University, Guangzhou 510055, China

${ }^{3}$ Guangdong Provincial Key Laboratory of Stomatology, Sun Yat-sen

University, Guangzhou, Guangdong, China

Full list of author information is available at the end of the article
}

(c) The Author(s). 2019 Open Access This article is distributed under the terms of the Creative Commons Attribution 4.0 International License (http://creativecommons.org/licenses/by/4.0/), which permits unrestricted use, distribution, and reproduction in any medium, provided you give appropriate credit to the original author(s) and the source, provide a link to the Creative Commons license, and indicate if changes were made. The Creative Commons Public Domain Dedication waiver (http://creativecommons.org/publicdomain/zero/1.0/) applies to the data made available in this article, unless otherwise stated. 


\section{Introduction}

Dental pulp regeneration may be a potential treatment for managing permanent teeth undergoing necrosis [1]. Regenerative endodontic therapy has been assayed with multiple mesenchymal stem cells (MSCs), growth factors, and biological materials [2, 3]. Magnesiumcontaining scaffolds are considered to be ideal biomaterials for such treatment, with the properties of releasing $\mathrm{Mg}^{2+}$ to enhance dentin regeneration in MSCs [4].

As reported, $\mathrm{Mg}^{2+}$ acts as an intracellular second messenger connecting cell-surface receptor induction and cytosolic effectors [5]. $\mathrm{Mg}^{2+}$ is the fourth most abundant cation in the human body and is critical for ATPdependent phosphorylation of DNA, RNA, and enzymes, and the average $\mathrm{Mg}^{2+}$ concentration in dentin is about $1 \%$ (wt/wt) [6-8]. $\mathrm{Mg}^{2+}$ is involved in the bio-mineralization of bones and teeth and directly affects crystallization and pattern generation of the inorganic mineral phase [8-10]. Evidence indicates mutations of the $\mathrm{Mg}^{2+}$ transporters TRPM7 and CNNM4 result in deficient dentin mineralization, confirming $\mathrm{Mg}^{2+}$ involvement in tooth development $[11,12]$. Animals fed low $\mathrm{Mg}^{2+}$ diets show deficient dentin and enamel mineralization [13]. Our previous study also demonstrates that the $\mathrm{Mg}^{2+}$ transporter Magt1 plays an important role in odontogenic differentiation of bone marrow MSCs by regulating intracellular $\mathrm{Mg}^{2+}$ [14]. Studies have found high extracellular $\mathrm{Mg}^{2+}$ and its transporter regulate odontogenic differentiation in human DPSCs, with involvement in dentin mineralization $[4,15]$.

However, the regulatory mechanisms of $\mathrm{Mg}^{2+}$ effects on odontogenic differentiation in DPSCs remain undefined. Till now, the altered transcriptome of DPSCs undergoing odontogenic differentiation induced by an $\mathrm{Mg}^{2+}$-enriched microenvironment has not been assessed; thus, we determine the alteration of transcriptome using RNA sequencing. Moreover, we aim to clarify the role of $\mathrm{Mg}^{2+}$-enriched microenvironment in odontogenic differentiation of DPSCs and determine the associated signaling pathways.

\section{Materials and methods}

\section{DPSC isolation and identification}

Studies involving patients had approval from the Ethics Committee of Sun Yat-Sen University. DPSCs were collected from non-diseased pulp tissues of caries-free third molars of patients. DPSCs were isolated according to a previous report [16] and maintained in $\alpha$-MEM containing $10 \%$ FBS (GIBCO, USA) and $10 \mathrm{mg} / \mathrm{mL}$ streptomycin and $10 \mathrm{U} / \mathrm{mL}$ penicillin (Sigma, USA). DPSCs at passages 3 to 7 were used in experiments. Flow cytometry analysis was performed to investigate DPSCs for surface markers. DPSCs were incubated with conjugated human antibodies, including CD45-PE, CD73-PE, CD90-APC, and CD166$\mathrm{PE}$ (BD, USA), and assessed flow cytometrically (BD,
USA). For confirming the adipogenic differentiation potential of stem cells, DPSCs underwent induction for 28 days with adipogenic medium containing $0.5 \mu \mathrm{M}$ isobutylmethylxanthine, $50 \mu \mathrm{M}$ indomethacin, $0.5 \mu \mathrm{M}$ dexamethasone, and $5 \mu \mathrm{g} / \mathrm{mL}$ insulin (Sigma, USA). To evaluate osteoblastic differentiation, DPSCs underwent culture for 14 days in osteogenic medium containing $100 \mathrm{nM}$ dexamethasone, $10 \mathrm{mM} \quad \beta$-glycerophosphate, and $0.2 \mathrm{mM}$ ascorbic acid (Sigma, USA).

\section{Determination of DPSC proliferation}

DPSCs seeded in 96-well plates at 1000 cells/well underwent culture in growth medium after addition of $0,1,5$, or $10 \mathrm{mM} \mathrm{MgCl}_{2}$ for 1 , 2, and 3 days, respectively. Cell Counting Kit-8 (Dojindo, Japan) was applied as directed by the manufacturer.

\section{Odontogenic differentiation of DPSCs induced by the $\mathrm{Mg}^{2+}$-enriched microenvironment}

DPSCs seeded in 12-well plates at $3 \times 10^{4}$ cells/well underwent culture in $\alpha$-MEM containing $10 \%$ FBS at $37^{\circ} \mathrm{C}$. At $80 \%$ confluency, DPSC culture was performed in odontogenic medium with $100 \mathrm{nM}$ dexamethasone, $10 \mathrm{mM} \beta$-glycerophosphate, and $0.2 \mathrm{mM}$ ascorbic acid, with the addition of $0,1,5$, or $10 \mathrm{mM} \mathrm{MgCl}_{2}$, respectively. After 7 days, the protein amounts of RUNX2, DSP, and DMP-1 were determined by automated immunoblot. After 14 days, mineralization nodules were assessed by Alizarin red S staining.

\section{Alizarin red S staining}

Alizarin red S (Sigma, USA) staining was carried out as proposed by the manufacturer. Destaining was performed with $10 \%$ cetylpyridinium chloride monohydrate buffer for $30 \mathrm{~min}$, and optical density was obtained at $575 \mathrm{~nm}$. Relative extracellular matrix mineralization was calculated for each sample.

\section{Inhibition of $\mathrm{Mg}^{2+}$ entry by 2-aminoethoxydiphenyl borate (2-APB)}

Given that TRPM7 was reported to transport $\mathrm{Mg}^{2+}$ across the cell membrane, we inhibited $\mathrm{Mg}^{2+}$-entry by treatment with $100 \mu \mathrm{M}$ of the TRPM7 inhibitor 2-APB (Aladdin, China) [17].

\section{Automated immunoblot}

Total protein from DPSCs was obtained with RIPA (Cell Signaling, USA). Automated immunoblot was carried out with Simple Wes (Protein Simple, USA) as directed by the manufacturer. In brief, $2.5 \mu \mathrm{g}$ total protein samples were mixed with the standard fluorescent master mix and added to prefilled Wes assay plates, alongside antibody diluent (Protein Simple); primary antibodies targeting BMP2 (Affinity, USA), 


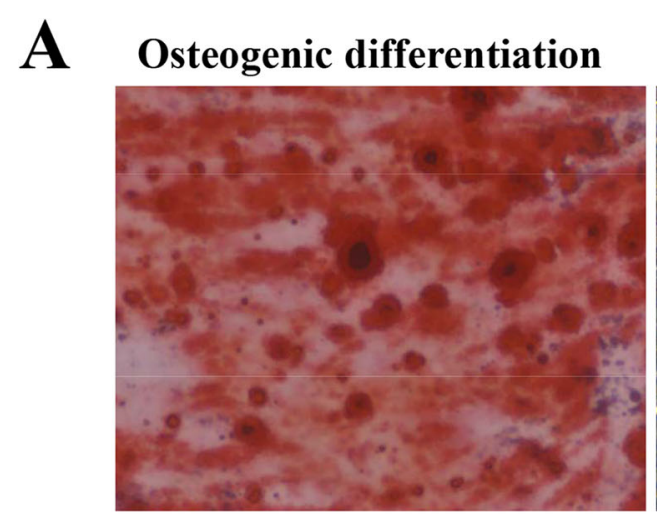

\section{Adipogenic differentiation}
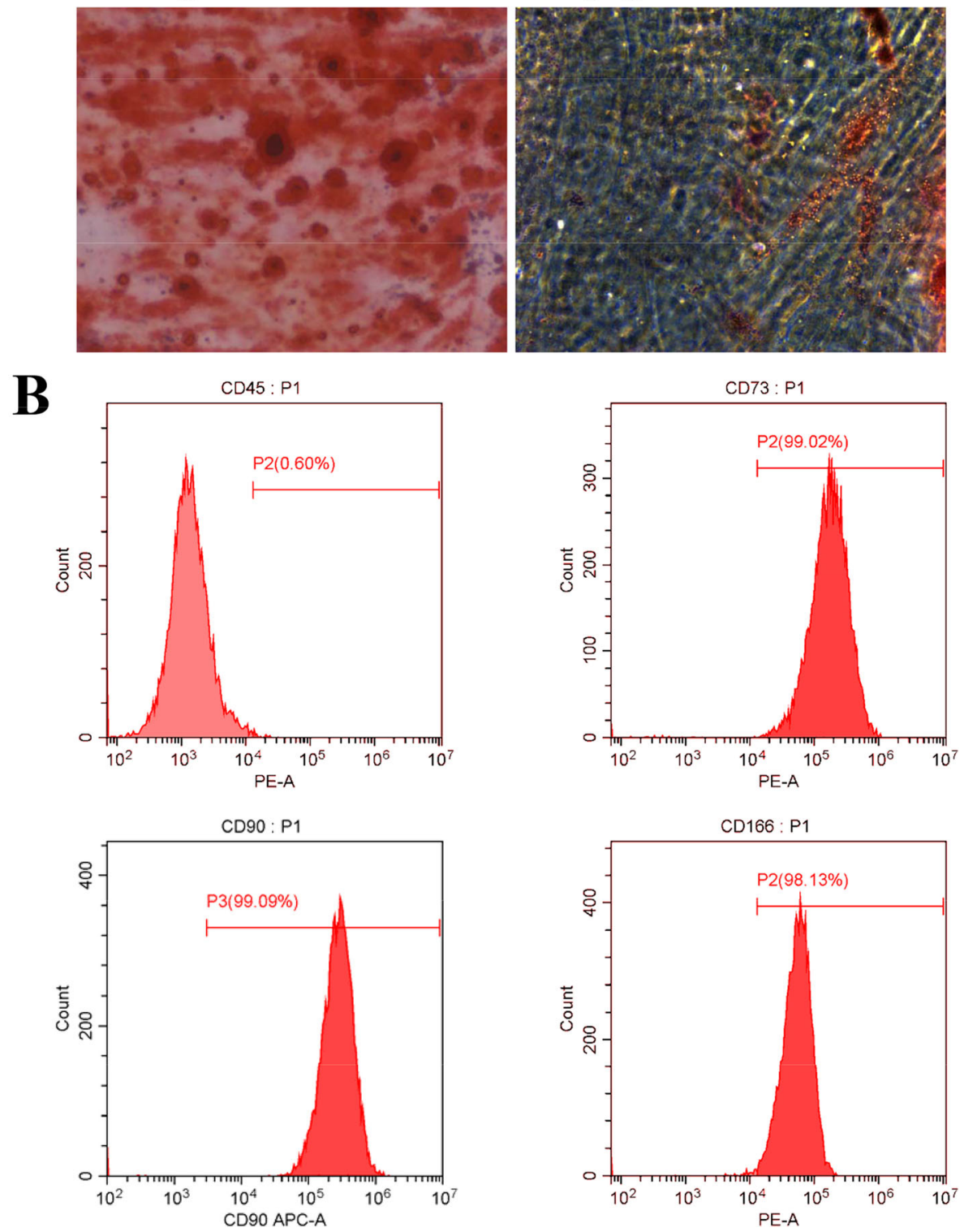

Fig. 1 Identification of DPSCs. a Mineral deposits stained by Alizarin Red S in DPSCs following osteogenic differentiation for 2 weeks. Adipocyte staining by Oil Red $\mathrm{O}$ upon adipoinduction for 4 weeks. b The expression rates of CD45, CD73, CD90, and CD166 are shown

BMPR1 (Affinity), p-Smad1/5/9 (Affinity), RUNX2 (Affinity), DSP (Santa Cruz, USA), DMP-1 (Genetex, USA), ERK, p-ERK, JNK, p-JNK, p38, p-p38 (Cell Signaling), and $\beta$-Tublin (Affinity, USA) were probed; anti-rabbit and anti-mouse secondary antibodies conjugated to Streptavidin-HRP (Protein Simple) were used for detection. The compass software (Protein Simple) was utilized for analysis.

Flow cytometry evaluation of intracellular magnesium Intracellular magnesium amounts in DPSCs were assessed with Mag-Fluo-4-AM (Invitrogen, USA) as directed by the manufacturer. Briefly, Mag-Fluo-4-AM was added at $2 \mu \mathrm{M}$ and incubated for $30 \mathrm{~min}$. This was followed by three cell washes. Fluorescence intensities were obtained by flow cytometry (BD, USA) in triplicate assays.

\section{RNA sequencing (RNA-seq)}

RNA-seq was carried out according to our previous work [14]. Briefly, DNase I treated total RNA specimens were enriched for mRNA using Oligo (dT) magnetic beads. Random-hexamer primers were employed for reverse transcription, and second-strand cDNA 


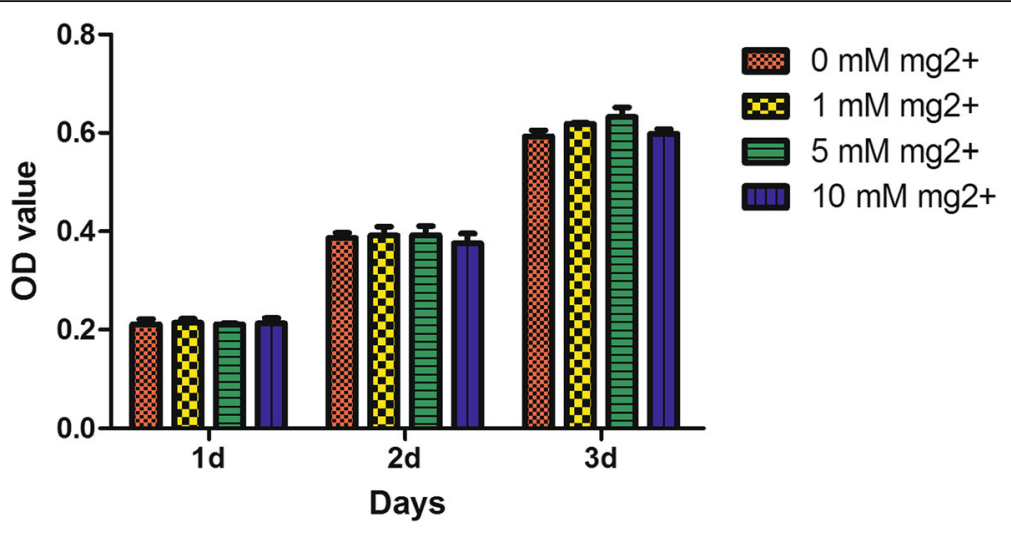

Fig. 2 Cell Counting Kit-8 analysis showing that $\mathrm{Mg}^{2+}$-enriched microenvironment has no effect on DPSC proliferation

synthesis was carried out with Second Strand cDNA Synthesis Kit (Beyotime, China) as directed by the manufacturer. Short fragment purification used the QiaQuick PCR extraction kit (Qiagen, the Netherlands). Sequencing adapters were next added to these short fragments. Suitable fragments were amplified, and an Illumina HiSeq $^{\text {Tw }} 2000$ (Illumina Inc., USA) was employed for the cDNA sequencing. False discovery rate (FDR) adjusted $p<0.05$ was obtained by the Benjamini-Hochberg method.

\section{GO and KEGG pathway analyses}

Gene Ontology (GO, http://www.geneontology.org) and Kyoto Encyclopedia of Genes and Genomes pathway (KEGG, http://www.genome.jp/kegg/pathway.html) analyses were carried out for determining biological functions and enriched metabolic or signal transduction pathways associated with the differentially expressed genes (DEGs), respectively.

\section{MAPK signaling assessment}

To assess MAPK signaling involvement, DPSCs underwent culture in 12-well plates in odontogenic medium with the addition of $0,1,5$, or $10 \mathrm{mM} \mathrm{MgCl}_{2}$ for 7 days, respectively. Then, total protein from DPSCs was isolated to measure the protein amounts of ERK, p-ERK, JNK, p-JNK, p38, and p-p38 by automated immunoblot. During odontogenic differentiation of DPSCs administered $5 \mathrm{mM} \mathrm{MgCl}_{2}$ for 7 days, ERK/MAPK signaling was suppressed with $50 \mu \mathrm{M}$ U0126 (AbMole BioScience, USA) for $2 \mathrm{~h}$ every 2 days.

\section{Statistical analysis}

Experiments were performed three times. Data were expressed as mean \pm SD and were assessed by ANOVA test with SPSS 17.0 (SPSS, USA); $p<0.05$ indicated statistical significance.

\section{Results}

Effects of the $\mathrm{Mg}^{2+}$-enriched microenvironment on proliferation and differentiation in DPSCs

Passage 3 DPSCs were examined. As shown in Fig. 1a, DPSCs could differentiate into osteoblasts and adipocytes, suggesting their multi-lineage differentiation potential. Flow cytometry analysis showed DPSCs had low CD45 (hematopoietic cell marker) amounts (0.60\%), but elevated amounts of the mesenchymal stem cell markers CD73 (99.02\%), CD90 (99.09\%), and CD166 (98.13\%) (Fig. 1b).

To evaluate the impact of high extracellular $\mathrm{Mg}^{2+}$ on their proliferation, DPSCs underwent incubation in $\mathrm{Mg}^{2+}$ enriched media at different concentrations $(0 \mathrm{mM}, 1 \mathrm{mM}$, $5 \mathrm{mM}$, and $10 \mathrm{mM}$ ) for 1,2 , and 3 days, respectively. Cell Counting Kit-8 analysis showed that high extracellular $\mathrm{Mg}^{2+}$ did not affect DPSC proliferation (Fig. 2).

To analyze the impact of high extracellular $\mathrm{Mg}^{2+}$ on their differentiation, DPSCs were cultured in $\mathrm{Mg}^{2+}$ enriched odontogenic medium at different concentrations $(0 \mathrm{mM}, 1 \mathrm{mM}, 5 \mathrm{mM}$, and $10 \mathrm{mM})$. After 7 days, RUNX2, DMP-1, and DSP protein amounts were markedly elevated in DPSCs treated with $1 \mathrm{mM}, 5 \mathrm{mM}$, and $10 \mathrm{mM} \mathrm{Mg}^{2+}$, respectively, compared with $0 \mathrm{mM} \mathrm{Mg}^{2+}$ (Fig. 3a). Consistently, mineralization nodules were also markedly increased (Fig. 3b). However, there was no difference between the 5 and $10 \mathrm{mM} \mathrm{Mg}^{2+}$ groups (Fig. 3). These results showed that the $\mathrm{Mg}^{2+}$-enriched microenvironment promoted the odontogenic differentiation of DPSCs.

\section{$\mathrm{Mg}^{2+}$-enriched microenvironment promotes} odontogenesis in DPSCs by increasing intracellular $\mathrm{Mg}^{2+}$ Intracellular magnesium levels in DPSCs treated with $\mathrm{Mg}^{2+}$-enriched odontogenic media at different concentrations $(0 \mathrm{mM}, 1 \mathrm{mM}, 5 \mathrm{mM}$, and $10 \mathrm{mM})$ were assessed flow cytometrically using Mag-Fluo-4-AM. 

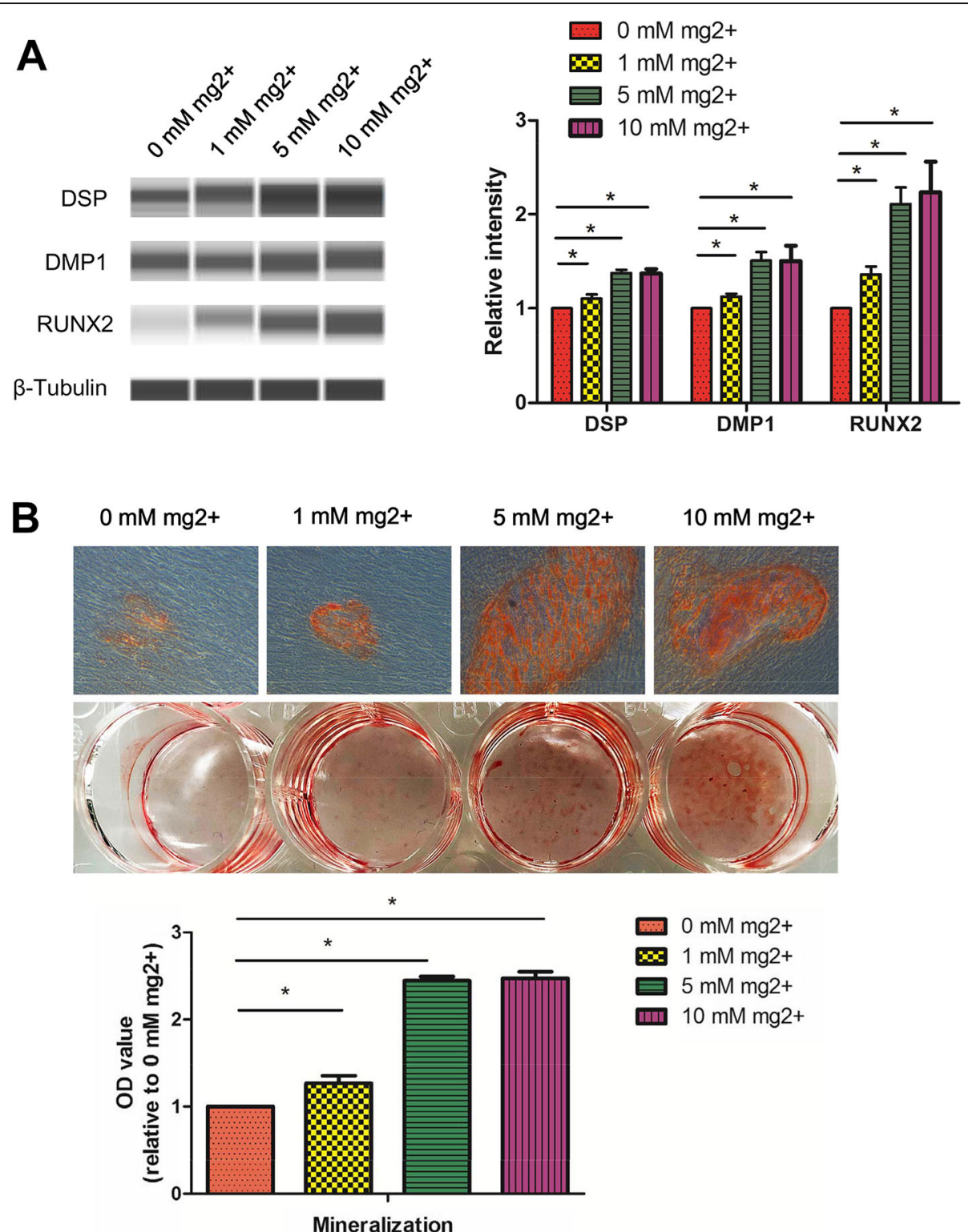

Fig. 3 Effects of $\mathrm{Mg}^{2+}$-enriched microenvironment on DPSC differentiation. a After 7 days, RUNX2, DMP-1, and DSP protein amounts were markedly elevated in DPSCs treated with $1 \mathrm{mM}, 5 \mathrm{mM}$, and $10 \mathrm{mM} \mathrm{Mg}^{2+}$, compared with the $0 \mathrm{mM} \mathrm{Mg}^{2+}$ group. b Consistently, mineralization nodules were also markedly increased after 14 days. However, there was no difference between the 5 and $10 \mathrm{mM} \mathrm{Mg}^{2+}$ groups

Figure 4a suggests that intracellular $\mathrm{Mg}^{2+}$ was starkly increased in DPSCs treated with $1 \mathrm{mM}, 5 \mathrm{mM}$, and 10 $\mathrm{mM} \mathrm{Mg}^{2+}$, compared with the $0 \mathrm{mM} \mathrm{Mg}^{2+}$ group. However, there was no difference in intracellular magnesium of DPSCs treated with $5 \mathrm{mM}$ and $10 \mathrm{mM} \mathrm{Mg}^{2+}$, which is consistent with their comparable effects on odontogenic differentiation.

Given that TRPM7 was reported to transport $\mathrm{Mg}^{2+}$ across the cell membrane [17], we next examined the effects of its blocker 2-APB. The results showed that $\mathrm{Mg}^{2+}$ entry was significantly blunted by 2 -APB $(100 \mu \mathrm{M}$, inhibiting TRPM7 [17]) (Fig. 4b). The positive effect of high extracellular $\mathrm{Mg}^{2+}\left(5 \mathrm{mM} \mathrm{Mg}{ }^{2+}\right)$ on odontogenic differentiation of DPSCs was also blocked by 2-APB (Fig. 4c). These results indicated that high extracellular $\mathrm{Mg}^{2+}$ promoted odontogenic differentiation in DPSCs via intracellular $\mathrm{Mg}^{2+}$ increase.

High extracellular $\mathrm{Mg}^{2+}$ alters the transcriptome of DPSCs Compared with control cells $\left(0 \mathrm{mM} \mathrm{Mg}{ }^{2+}\right)$, exposure to high extracellular $\mathrm{Mg}^{2+}\left(5 \mathrm{mM} \mathrm{Mg}^{2+}\right)$ for 7 days resulted in 734 DEGs in DPSCs, including 250 upregulated and 484 downregulated (Fig. 5a, b). 


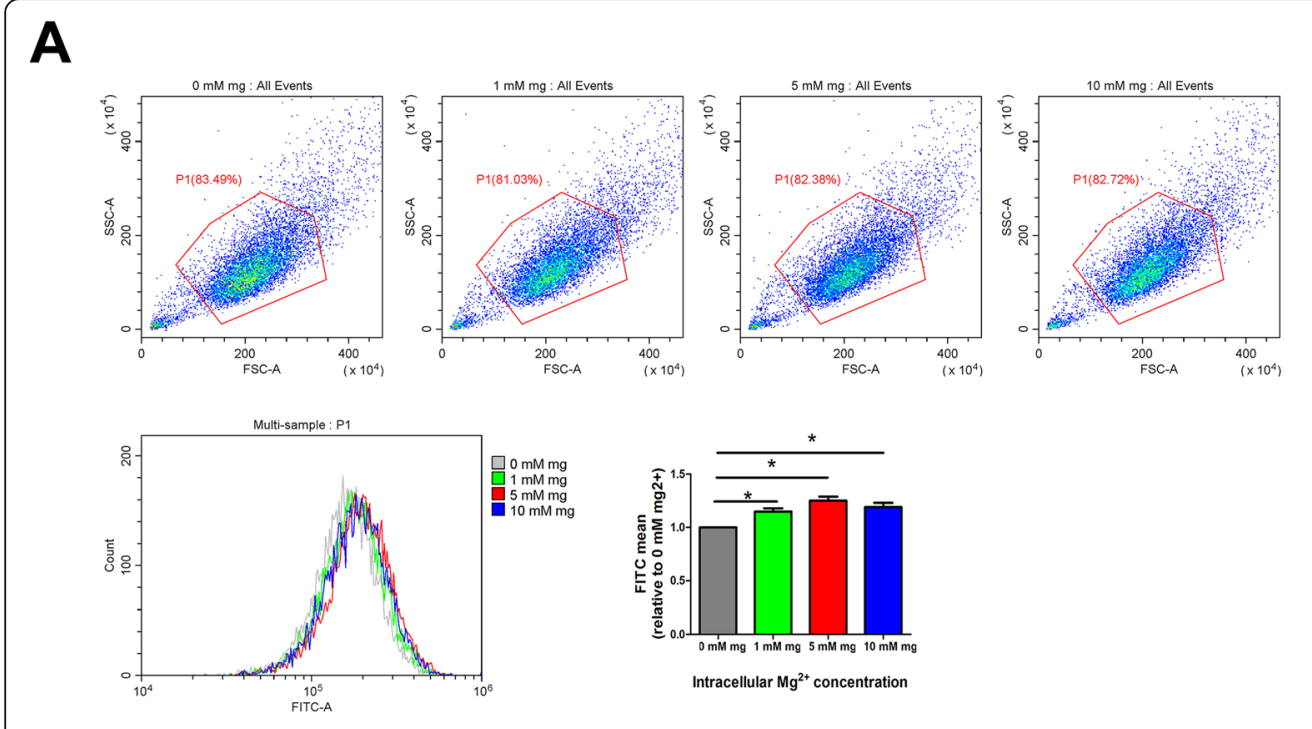

B
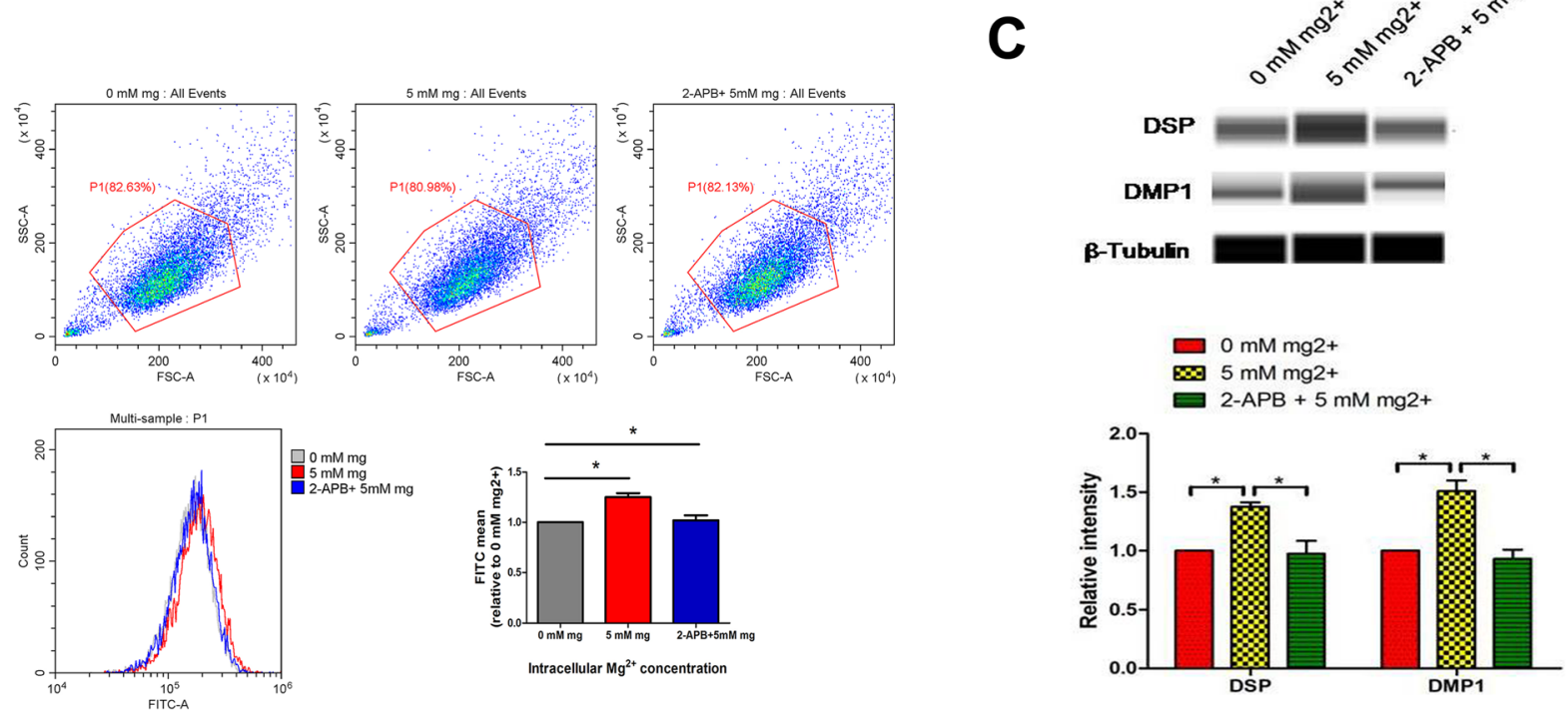

Fig. $4 \mathrm{Mg}^{2+}$-enriched microenvironment promotes odontogenic differentiation in DPSCs by increasing intracellular $\mathrm{Mg}^{2+}$. a Intracellular $\mathrm{Mg}^{2+}$ was significantly increased in DPSCs exposed to high extracellular $\mathrm{Mg}^{2+}$ as assessed flow cytometrically using Mag-Fluo-4-AM; however, there was no difference between the 5 and $10 \mathrm{mM} \mathrm{Mg}^{2+}$ groups. $\mathbf{b} \mathrm{Mg}^{2+}$-entry was significantly inhibited by the TRPM7 inhibitor 2-APB. c The positive effect of $\mathrm{Mg}^{2+}$-enriched microenvironment on odontogenic differentiation in DPSCs was also blocked by 2-APB

\section{GO and KEGG pathway analyses of DEGs}

In GO analysis, DEGS were mostly involved in developmental process, anatomical structure development, organism development, system development, channel activity, metal ion binding, integral component of plasma membrane, etc. (Fig. 5c). KEGG pathway analysis indicated that the DEGs retrieved participated in many pathways, e.g., MAPK and TGF- $\beta$ pathways (Fig. $5 \mathrm{~d}$ ).

\section{ERK signaling is activated by high extracellular $\mathrm{Mg}^{2+}$} during odontogenic differentiation of DPSCs

As shown above, KEGG pathway analysis revealed MAPK signaling activation by high extracellular
$\mathrm{Mg}^{2+}$ during odontogenic differentiation of DPSCs. To verify this finding, DPSCs were incubated in odontogenic medium with the addition of $0,1,5$, and 10 $\mathrm{mM} \mathrm{MgCl}_{2}$ for 7 days, respectively. The results showed that ERK phosphorylation was markedly enhanced in DPSCs treated with $1 \mathrm{mM}, 5 \mathrm{mM}$, and 10 $\mathrm{mM} \mathrm{Mg}{ }^{2+}$ compared with the $0 \mathrm{mM} \mathrm{Mg}{ }^{2+}$ group, but p38 and JNK phosphorylation showed no change (Fig. 6a). In accordance, the positive effect of high extracellular $\mathrm{Mg}^{2+}$ on ERK phosphorylation was blocked by 2 -APB $(100 \mu \mathrm{M}$, inhibiting TRPM7) (Fig. 6b), which reduced intracellular $\mathrm{Mg}^{2+}$ amounts (Fig. 4b). 


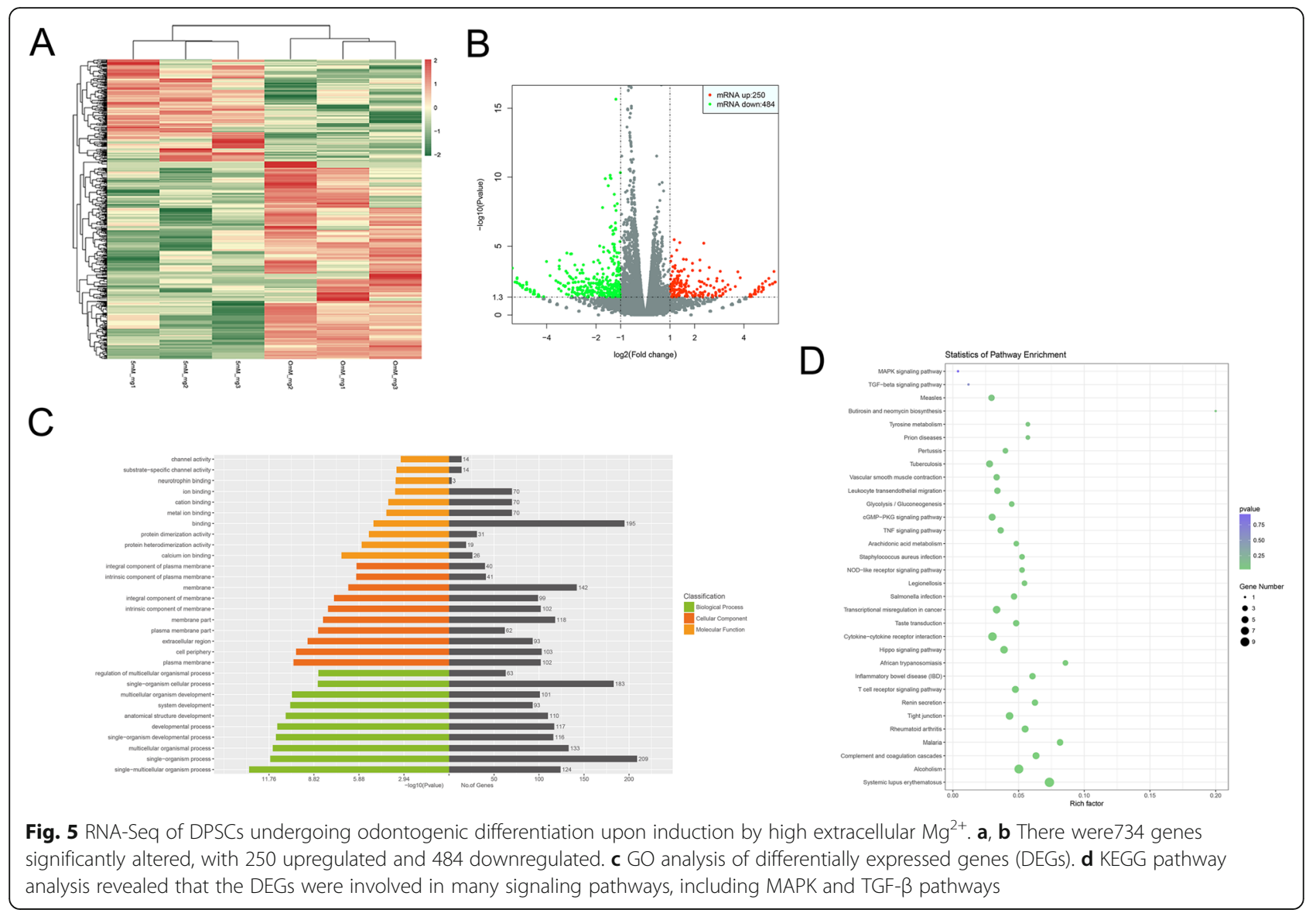

BMP2/Smads signaling is activated by high extracellular $\mathrm{Mg}^{2+}$ during odontogenic differentiation of DPSCs

As reported previously, BMP2 is a TGF- $\beta$ family member controlling odontogenic differentiation of stem cells $[18,19]$. To verify the above KEGG pathway data, we performed Western blot to determine whether BMP2/Smads signaling is activated by high extracellular $\mathrm{Mg}^{2+}$. The results showed that BMP2, BMPR1, and phosphorylated Smad1/5/9 were significantly increased in DPSCs cultured in odontogenic medium containing high extracellular $\mathrm{Mg}^{2+}$ (Fig. 6c). In accordance, the positive effects of high extracellular $\mathrm{Mg}^{2+}$ on BMP2, BMPR1, and phosphorylated Smad1/5/9 were blocked by 2 -APB $(100 \mu \mathrm{M}$, inhibiting TRPM7) (Fig. 6d).

\section{$\mathrm{Mg}^{2+}$-enriched microenvironment promotes odontogenic differentiation in DPSCs via ERK/BMP2/Smads signaling} We inhibited ERK signaling with U0126, and mineralization nodules were markedly decreased, as well as RUNX2, DSP, and DMP-1 protein amounts in DPSCs treated with $\mathrm{Mg}^{2+}$-enriched odontogenic medium (5 mM $\mathrm{Mg}^{2+}$ ) for 7 days (Fig. 7a,b). Interestingly, BMP2, BMPR1, and phosphorylated Smad1/5/9 amounts were also significantly decreased by U0126, indicating that BMP2/ Smads acted as downstream of ERK (Fig. 7c).

Taken together, these findings suggested that $\mathrm{Mg}^{2+}$ enriched microenvironment promoted odontogenic differentiation in DPSCs by activating ERK/BMP2/ Smads signaling via intracellular $\mathrm{Mg}^{2+}$ increase (Fig. 8).

\section{Discussion}

Regenerative endodontic therapy involves biological procedures for replacing damaged dental structures such as dentin and root, and cells of the dentin/pulp complex [20]. DPSCs are suitable for such treatment, and their differentiation into odontogenic stem cells associated with biomaterials and growth factors is critical for dental pulp regeneration [1]. It is known that magnesium-containing scaffolds are ideal tools for regenerative endodontic therapy, releasing high extracellular $\mathrm{Mg}^{2+}$ to enhance dentin regeneration in DPSCs [4]. Our previous studies found the $\mathrm{Mg}^{2+}$ transporters TRPM7 and MagT1 regulate odontogenic differentiation in stem cells $[14,15]$. Nakano and collaborators [12] reported that TRPM7 silencing in mice results in marked tooth hypomineralization, suggesting TRPM7 to be involved in enamel and dentin biomineralization by supplying enough $\mathrm{Mg}^{2+}$ for ALPL activity. Luder and 


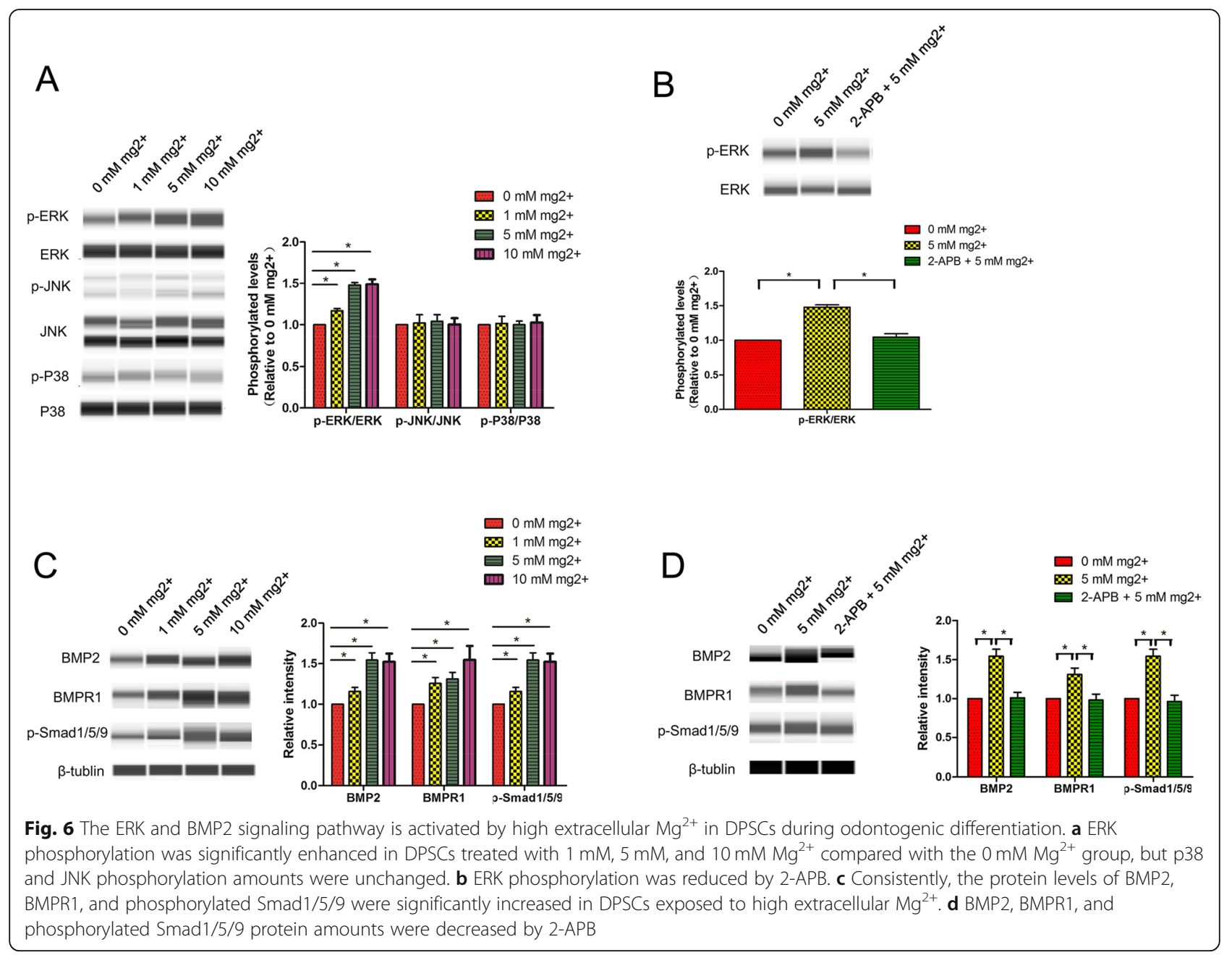

colleagues [11] demonstrated that mutation of CNNM4, a $\mathrm{Mg}^{2+}$ transporter, caused mineralization abnormalities in both enamel and dentin, in association with starkly reduced magnesium amounts. Consistent with previous studies, the present work determined that $\mathrm{Mg}^{2+}$-enriched microenvironment enhanced odontogenic differentiation in DPSCs by altering the formation of mineralization nodules as well as RUNX2, DMP-1, and DSP protein amounts, through intracellular $\mathrm{Mg}^{2+}$ concentration increase.

However, how high extracellular $\mathrm{Mg}^{2+}$ affects odontogenic differentiation remains unknown. Therefore, RNASeq was carried out to assess transcriptome alterations in DPSCs exposed to $\mathrm{Mg}^{2+}$-enriched microenvironment. Interestingly, GO and KEGG pathway analyses revealed 734 DEGs contributing to odontogenic differentiation in DPSCs induced by high extracellular $\mathrm{Mg}^{2+}$. The obtained DEGs participated in many pathways, such as MAPK and TGF- $\beta$ pathways.

MAPK signaling regulates stem cell proliferation, migration, and differentiation [21-23]. Yu and colleagues
[24] demonstrated that dentine matrix promoted odontogenic differentiation in bone marrow MSCs by inducing ERK and P38 MAPK pathways. Huang and collaborators [25] revealed that dental pulp cell-derived exosomes promote odontogenic differentiation in bone marrow MSCs via P38/MAPK signaling. As reported in previous studies, MAPK signaling also contributes to odontogenic differentiation in DPSCs [26]. In the present study, ERK phosphorylation was significantly increased in DPSCs treated with high extracellular $\mathrm{Mg}^{2+}$, but p38 and JNK phosphorylation levels remained unchanged, indicating ERK/MAPK signaling is induced by high extracellular $\mathrm{Mg}^{2+}$. Consistently, blunting ERK/MAPK signaling with U0126 blocked the effects of high extracellular $\mathrm{Mg}^{2+}$ on mineralization and odontogenic differentiation in DPSCs.

According to previous studies, intracellular $\mathrm{Mg}^{2+}$ plays a pivotal role in ERK/MAPK signaling induction [27-30]. For example, $\mathrm{Mg}^{2+}$ deprivation downregulates p-ERK1/2 in MDCK cells, and $\mathrm{Mg}^{2+}$ re-supplementation reverses this effect $[29,30]$. Meanwhile, TRPM7 suppression inhibits ERK phosphorylation by reducing 

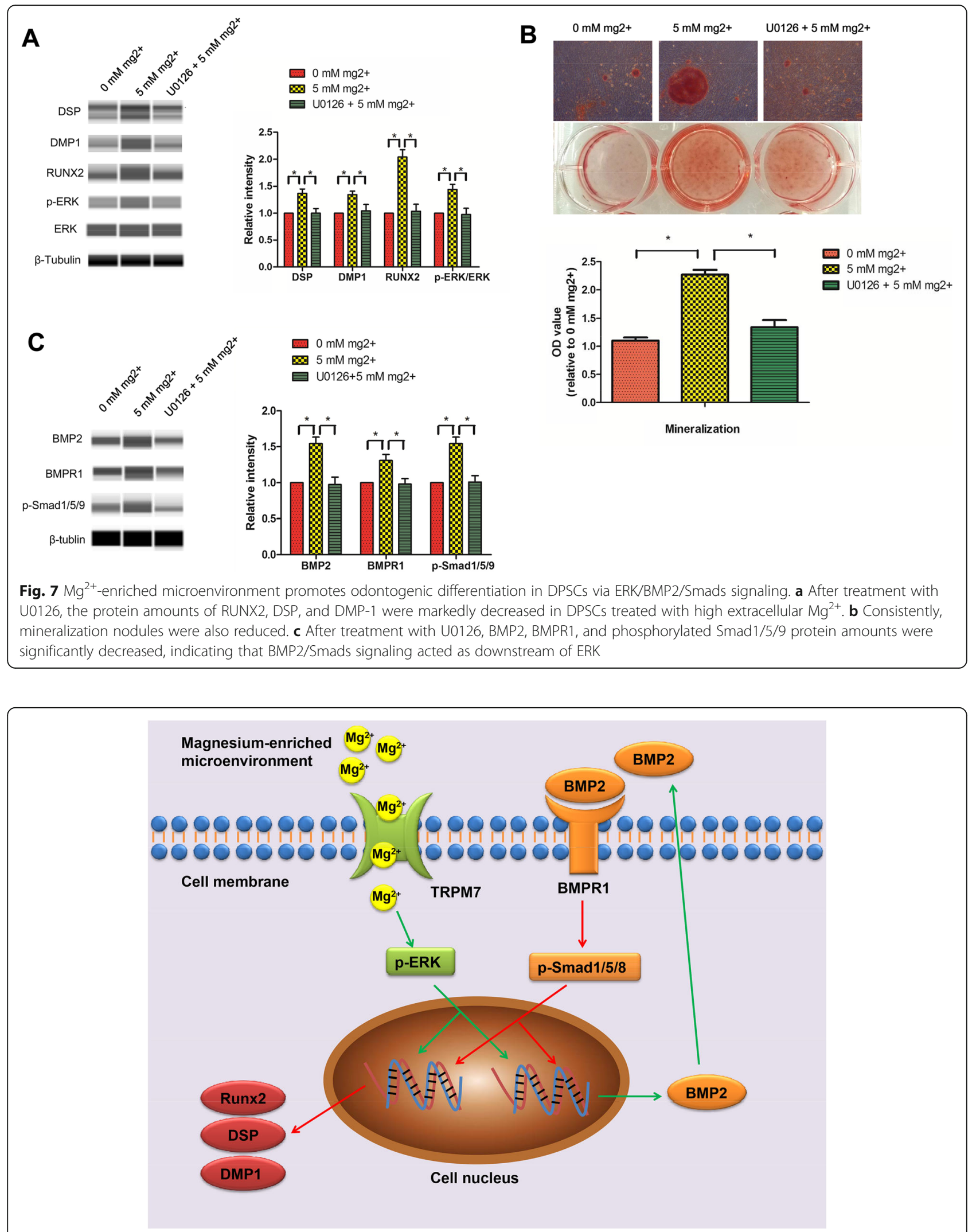

Fig. 8 Summary diagram. $\mathrm{Mg}^{2+}$-enriched microenvironment promotes odontogenic differentiation in DPSCs by activating ERK/BMP2/Smads signaling via intracellular $\mathrm{Mg}^{2+}$ increase 
intracellular $\mathrm{Mg}^{2+}$ amounts $[27,28]$. Our previous studies also revealed that suppression of MagT1 inactivates the ERK/MAPK pathway by decreasing intracellular $\mathrm{Mg}^{2+}$, which results in inhibited odontogenic differentiation of bone marrow MSCs [14]. In the present study, intracellular magnesium in DPSCs exposed to high extracellular $\mathrm{Mg}^{2+}$ was assessed flow cytometrically with Mag-Fluo-4-AM. As shown above, intracellular $\mathrm{Mg}^{2+}$ amounts were starkly increased in DPSCs treated with high extracellular $\mathrm{Mg}^{2+}$. In accordance, the positive effect of high extracellular $\mathrm{Mg}^{2+}$ on ERK phosphorylation was blocked by $2-\mathrm{APB}$, which reduces intracellular $\mathrm{Mg}^{2+}$ amounts, indicating that high extracellular $\mathrm{Mg}^{2+}$ activates ERK/MAPK signaling by increasing intracellular $\mathrm{Mg}^{2+}$.

BMP2, a member of the TGF- $\beta$ family of proteins, contributes to odontogenic differentiation in DPSCs $[18,19]$. Consistent with KEGG pathway data, BMP2, BMPR1, and phosphorylated Smad1/5/9 amounts were significantly increased in DPSCs incubated in $\mathrm{Mg}^{2+}$-enriched odontogenic media. As expected, the positive effects of high extracellular $\mathrm{Mg}^{2+}$ on BMP2, BMPR1, and phosphorylated Smad1/5/9 were blocked by the $\mathrm{Mg}^{2+}$ transporter inhibitor $2-\mathrm{APB}$, indicating that $\mathrm{BMP} 2 / \mathrm{Smads}$ signaling is activated during odontogenic differentiation induced by $\mathrm{Mg}^{2+}$ enriched microenvironment. This finding corroborated Cheng et al. [31] showing that high-purity magnesium scaffolds promote bone regeneration in rabbits via activation of BMP2 signaling by releasing high amounts of extracellular $\mathrm{Mg}^{2+}$.

Interestingly, ERK signaling inhibition by U0126 resulted in significantly decreased BMP2, BMPR1, and phosphorylated Smad1/5/9 amounts, indicating that BMP2/Smads is a downstream signaling of ERK. Taken together, these findings demonstrated that high extracellular $\mathrm{Mg}^{2+}$ promotes odontogenic differentiation in DPSCs by activating ERK/BMP2/Smads signaling via intracellular $\mathrm{Mg}^{2+}$ increase.

\section{Conclusions}

Overall, significant transcriptome alterations were detected in DPSCs during odontogenic differentiation associated with high extracellular $\mathrm{Mg}^{2+}$. In addition, $\mathrm{Mg}^{2+}$ enriched microenvironment enhanced odontogenic differentiation in DPSCs by activating ERK/BMP2/Smads signaling via intracellular $\mathrm{Mg}^{2+}$ increase.

\section{Abbreviations}

RNA-Seq: RNA-Sequencing: MAPK: Mitogen-activated protein kinase; ERK: Extracellular signal-related kinase; JNK: c-Jun NH2-terminal kinase; DSP: Dentin sialophosphoprotein; DMP-1: Dentin matrix protein 1; GO: Gene Ontology; RUNX2: Runt-related transcription factor 2; BMP2: Bone morphogenetic protein 2; BMPR1: Bone morphogenetic protein receptor 1

Acknowledgements

Not applicable.

\section{Authors' contributions}

JZ and BW conceived this study. JZ, Y-yK, XH, and YZ performed the experiments, as well as data collection and analysis. KX helped carry out the experiments. JZ, BW, and YK wrote the manuscript. All authors read and approved the final manuscript.

\section{Funding}

The present work was funded by the Natural Science Foundation of Guangdong Province (No.2019A1515011289), National Natural Science Foundation of China (No.81700950), the Youth Teacher Training Project of Sun Yat-Sen University (No. 17ykpy74), Grant-in-Aid from Health and Family Planning Commission of Guangdong Province (No.A2017579), and the Bureau of Health of the Guangzhou Municipality (No.20171A011324).

\section{Availability of data and materials}

The authors confirm the availability of all data generated or analyzed in this manuscript.

\section{Ethics approval and consent to participate}

The study had approval from the Ethics Committee of Sun Yat-Sen University.

\section{Consent for publication}

Not applicable.

\section{Competing interests}

The authors declare that they have no competing interests.

\section{Author details}

'Department of Stomatology, Nanfang Hospital, College of Stomatology, Southern Medical University, Guangzhou 510055, China. ${ }^{2}$ Key Laboratory of Oral Medicine, Guangzhou Institute of Oral Disease, Department of Endodontics, Stomatology Hospital of Guangzhou Medical University, Guangzhou, Guangdong, China. ${ }^{3}$ Guangdong Provincial Key Laboratory of Stomatology, Sun Yat-sen University, Guangzhou, Guangdong, China.

${ }^{4}$ Department of Operative Dentistry and Endodontics, Guanghua School of Stomatology, Affiliated Stomatological Hospital, Sun Yat-sen University, Guangzhou 510055, Guangdong, China.

Received: 24 September 2019 Revised: 4 November 2019 Accepted: 13 November 2019 Published online: 10 December 2019

\section{References}

1. Xuan K, Li B, Guo H, Sun W, Kou X, He X, Zhang Y, Sun J, Liu A, Liao L, et al. Deciduous autologous tooth stem cells regenerate dental pulp after implantation into injured teeth. Sci Transl Med. 2018;10(455). https://doi.org/ 10.1126/scitranslmed.aaf3227.

2. Ravindran S, Huang CC, George A. Extracellular matrix of dental pulp stem cells: applications in pulp tissue engineering using somatic MSCs. Front Physiol. 2014:4:395.

3. Yang JW, Zhang YF, Sun ZY, Song GT, Chen Z. Dental pulp tissue engineering with bFGF-incorporated silk fibroin scaffolds. J Biomater Appl. 2015;30(2):221-9.

4. Qu T, Jing J, Jiang Y, Taylor RJ, Feng JQ, Geiger B, Liu X. Magnesiumcontaining nanostructured hybrid scaffolds for enhanced dentin regeneration. Tissue Eng A. 2014;20(17-18):2422-33.

5. Li FY, Chaigne-Delalande B, Kanellopoulou C, Davis JC, Matthews HF, Douek DC, Cohen II, Uzel G, Su HC, Lenardo MJ. Second messenger role for Mg2+ revealed by human T-cell immunodeficiency. Nature. 2011;475(7357):471-6.

6. Maguire ME, Cowan JA. Magnesium chemistry and biochemistry. Biometals. 2002;15(3):203-10.

7. Wolf Fl, Cittadini A. Chemistry and biochemistry of magnesium. Mol Asp Med. 2003:24(1-3):3-9.

8. Wiesmann HP, Tkotz T, Joos U, Zierold K, Stratmann U, Szuwart T, Plate U, Hohling HJ. Magnesium in newly formed dentin mineral of rat incisor. J Bone Miner Res. 1997:12(3):380-3

9. Todorovic T, Vujanovic D. The influence of magnesium on the activity of some enzymes (AST, ALT, ALP) and lead content in some tissues. Magnes Res. 2002;15(3-4):173-7.

10. Scibior A, Adamczyk A, Mroczka R, Niedzwiecka I, Golebiowska D, Fornal E. Effects of vanadium $(\mathrm{V}$ ) and magnesium $(\mathrm{Mg})$ on rat bone tissue: mineral 
status and micromorphology. Consequences of V-Mg interactions. Metallomics. 2014;6(12):2260-78.

11. Luder HU, Gerth-Kahlert C, Ostertag-Benzinger S, Schorderet DF. Dental phenotype in Jalili syndrome due to a c.1312 dupC homozygous mutation in the CNNM4 gene. PloS One. 2013;8(10):e78529.

12. Nakano Y, Le MH, Abduweli D, Ho SP, Ryazanova LV, Hu Z, Ryazanov AG, Den Besten PK, Zhang Y. A critical role of TRPM7 as an ion channel protein in mediating the mineralization of the craniofacial hard tissues. Front Physiol. 2016;7:258.

13. Trowbridge $H$, Louchard W, Jenks P. Histochemical studies on the dentin of magnesium-deficient rats. J Periodontal Res. 1971;6(2):130-9.

14. Zheng JM, Kong YY, Li YY, Zhang W. MagT1 regulated the odontogenic differentiation of BMMSCs induced byTGC-CM via ERK signaling pathway. Stem Cell Res Ther. 2019;10(1):48.

15. Cui L, Xu SM, Ma DD, Wu BL. The effect of TRPM7 suppression on the proliferation, migration and osteogenic differentiation of human dental pulp stem cells. Int Endod J. 2014;47(6):583-93.

16. Gronthos S, Mankani M, Brahim J, Robey PG, Shi S. Postnatal human dental pulp stem cells (DPSCs) in vitro and in vivo. Proc Natl Acad Sci U S A. 2000; 97(25):13625-30.

17. Zhang $Y$, Xu J, Ruan YC, Yu MK, O'Laughlin M, Wise H, Chen D, Tian L, Shi D, Wang J, et al. Implant-derived magnesium induces local neuronal production of CGRP to improve bone-fracture healing in rats. Nat Med. 2016;22(10):1160-9.

18. Zhang W, Zhang X, Li J, Zheng J, Hu X, Xu M, Mao X, Ling J. Foxc2 and BMP2 induce osteogenic/odontogenic differentiation and mineralization of human stem cells from apical papilla. Stem Cells Int. 2018;2018:2363917.

19. Zhang W, Zhang $X$, Ling J, Liu W, Zhang X, Ma J, Zheng J. Proliferation and odontogenic differentiation of BMP2 genetransfected stem cells from human tooth apical papilla: an in vitro study. Int J Mol Med. 2014;34(4): 1004-12.

20. Metlerska J, Fagogeni I, Nowicka A. Efficacy of autologous platelet concentrates in regenerative endodontic treatment: a systematic review of human studies. J Endod. 2019;45(1):20-30 e21.

21. Woo SM, Lim HS, Jeong KY, Kim SM, Kim WJ, Jung JY. Vitamin D promotes odontogenic differentiation of human dental pulp cells via ERK activation. Molecules and cells. 2015;38(7):604-9.

22. Shilo BZ. The regulation and functions of MAPK pathways in drosophila. Methods. 2014;68(1):151-9.

23. Cargnello M, Roux PP. Activation and function of the MAPKs and their substrates, the MAPK-activated protein kinases. Microbiol Mol Biol Rev. 2011;75(1):50-83.

24. Yu Y, Wang L, Yu J, Lei G, Yan M, Smith G, Cooper PR, Tang C, Zhang G, Smith AJ. Dentin matrix proteins (DMPs) enhance differentiation of BMMSCs via ERK and P38 MAPK pathways. Cell Tissue Res. 2014:356(1):171-82.

25. Huang CC, Narayanan R, Alapati S, Ravindran S. Exosomes as biomimetic tools for stem cell differentiation: applications in dental pulp tissue regeneration. Biomaterials. 2016;111:103-15.

26. Wu J, Li N, Fan Y, Wang Y, Gu Y, Li Z, Pan Y, Romila G, Zhou Z, Yu J. The conditioned medium of calcined tooth powder promotes the osteogenic and odontogenic differentiation of human dental pulp stem cells via MAPK signaling pathways. Stem Cells Int. 2019;2019:4793518.

27. Baldoli E, Maier JA. Silencing TRPM7 mimics the effects of magnesium deficiency in human microvascular endothelial cells. Angiogenesis. 2012; 15(1):47-57.

28. Zeng Z, Leng T, Feng X, Sun H, Inoue K, Zhu L, Xiong ZG. Silencing TRPM7 in mouse cortical astrocytes impairs cell proliferation and migration via ERK and JNK signaling pathways. PLoS One. 2015;10(3):e0119912.

29. Ikari A, Kinjo K, Atomi K, Sasaki Y, Yamazaki Y, Sugatani J. Extracellular Mg (2+) regulates the tight junctional localization of claudin-16 mediated by ERKdependent phosphorylation. Biochim Biophys Acta. 2010;1798(3):415-21.

30. Ikari A, Atomi K, Kinjo K, Sasaki Y, Sugatani J. Magnesium deprivation inhibits a MEK-ERK cascade and cell proliferation in renal epithelial Madin-Darby canine kidney cells. Life Sci. 2010;86(19-20):766-73.

31. Cheng P, Han P, Zhao C, Zhang S, Wu H, Ni J, Hou P, Zhang Y, Liu J, Xu H, et al. High-purity magnesium interference screws promote fibrocartilaginous entheses regeneration in the anterior cruciate ligament reconstruction rabbit model via accumulation of BMP-2 and VEGF. Biomaterials. 2016;81:14-26.

\section{Publisher's Note}

Springer Nature remains neutral with regard to jurisdictional claims in published maps and institutional affiliations.

\section{Ready to submit your research? Choose BMC and benefit from:}

- fast, convenient online submission

- thorough peer review by experienced researchers in your field

- rapid publication on acceptance

- support for research data, including large and complex data types

- gold Open Access which fosters wider collaboration and increased citations

- maximum visibility for your research: over $100 \mathrm{M}$ website views per year

At BMC, research is always in progress.

Learn more biomedcentral.com/submissions 